\title{
Rottlerin-Independent Attenuation of Pervanadate-Induced Tyrosine Phosphorylation Events by Protein Kinase C- $\delta$ in Hemopoietic Cells
}

\author{
Michael Leitges, Winfried Elis, Kerstin Gimborn, and Michael Huber \\ Max Planck Institute for Experimental Endocrinology (ML), Hannover; and Department of Molecular Immunology \\ (WE, KG, MH), Biology III, University of Freiburg and Max Planck Institute for Immunobiology, Freiburg, Germany
}

\begin{abstract}
SUMMARY: The understanding and control of many pathophysiological conditions is based on knowledge of subtly regulated intracellular signaling networks. We have found that in pervanadate (PV)-treated J558L myeloma cells, amongst other signaling proteins, protein kinase $\mathrm{C}(\mathrm{PKC})-\delta$ and src homology 2 -containing inositol phosphatase (SHIP) are tyrosine phosphorylated on expression of the B cell receptor, suggesting a role for these proteins in the preformed B cell receptor transducer complex. Rottlerin, a widely used PKC- $\delta$-specific inhibitor, efficiently blocks these PV-induced tyrosine phosphorylation events. Furthermore, PV treatment of bone marrow-derived mast cells (BMMC) also results in tyrosine phosphorylation of PKC- $\delta$, SHIP, and additional proteins. Rottlerin also inhibits these responses, indicating that PKC- $\delta$ might play an important enhancing role in the propagation of phosphotyrosine signals in B cells and mast cells and hence in the regulation of function of both cell types. Therefore, BMMC from PKC- $\delta-/-$ mice were generated by in vitro differentiation and assayed for tyrosine phosphorylation events in response to PV. Intriguingly, and opposite to the Rottlerin data, PKC- $\delta-/-$ BMMC show a stronger response to PV than wild-type cells, suggesting an attenuating role for PKC- $\delta$. This response can be inhibited equally well by Rottlerin, indicating clearly that Rottlerin is not specific for PKC- $\delta$ in vivo. A comparison between Rottlerin and the panspecific PKC inhibitor bisindolylmaleimide suggests that Rottlerin also targets kinases beyond the PKC family. Moreover, Ser473 phosphorylation of protein kinase B (PKB) after PV treatment is blocked by Rottlerin as efficiently as by the phosphatidylinositol 3-kinase inhibitor LY294002. In this report, we provide evidence that PKC- $\delta$ constitutes a crucial attenuating factor in B cell and mast cell signal transduction and suggest that PKC- $\delta$ is important for the regulation of physiological B and mast cell functions as well as for their pathophysiology. Furthermore, dominant PKC- $\delta$-independent effects of Rottlerin are presented, indicating restrictions of this inhibitor for use in signal transduction research. (Lab Invest 2001, 81:1087-1095).
\end{abstract}

\begin{abstract}
I resting cells, signaling pathways are under the 1 equilibrium control of activating enzymes (eg, kinases) and inhibiting enzymes (eg, phosphatases). Cellular activation can be envisaged as a shift of equilibrium either by the potentiation of activating enzymes, by the blockade of inhibiting enzymes, or most probably, by a combination of both. A way of modifying this intracellular equilibrium between phosphorylation and dephosphorylation is by treating living cells with the potent inhibitor of protein tyrosine phosphatases pervanadate/ $\mathrm{H}_{2} \mathrm{O}_{2}$ (PV) (Campbell et al, 1995; Hecht and Zick, 1992; Imbert et al, 1994; O'Shea et al, 1992; Secrist et al, 1993). The use of this drug for stimulating $B$ cell receptor (BCR)-negative J558L cells and IgM-BCR-positive transfectants of J558L ( $\mu \mathrm{m} 3-11$ ) revealed an almost exclusive tyrosine phosphorylation of several substrate proteins in $\mu \mathrm{m}$ 3-11 cells, showing a pattern similar to that
\end{abstract}

Received March 20, 2001.

This work is supported by the Deutsche Forschungsgemeinschaft through grant SFB 388 and the Leibniz prize to Dr. M. Reth, Max Planck Institute for Immunobiology, Freiburg, Germany.

Address reprint requests to: Dr. Michael Huber, Max Planck Institute for Immunobiology, Stübeweg 51, 79108 Freiburg, Germany. E-mail: huberm@immunbio.mpg.de observed after BCR stimulation by antigen (Wienands et al, 1996). These data suggested that the BCR on the surface of $B$ lymphocytes organizes its own transducer complex, which, containing kinases and phosphatases, can be activated by PV. Several proteins have been shown to participate in this BCR transducer complex, for example, the adapter protein SLP-65, the tyrosine kinases Lyn and Syk, and the BCR signal transducing components Ig- $\alpha$ and $\lg -\beta$ (Wienands et al, 1996). SLP-65 has recently been shown to be important for B cell development and signal transduction (Jumaa et al, 1999), and a patient deficient for SLP-65 was demonstrated to suffer from X-linked agammaglobulinemia (Minegishi et al, 1999). Further proteins of $80 \mathrm{kd}, 100 / 120 \mathrm{kd}$, and $>120 \mathrm{kd}$ were tyrosine phosphorylated in response to PV, but have not yet been identified. Because like SLP-65 these proteins might be important elements of the BCR transducer complex (Jumaa et al, 1999; Wienands et al, 1996), their identification might unravel new constituents of early BCR signal transduction as well as B cell-related diseases.

To date, several strategies to dissect signaling pathways have been successfully employed. One common approach is the use of small, cell-permeant inhibitors of protein kinases, which optimally inhibit a single 
enzyme and therefore allow the analysis of the contribution of one particular kinase to certain downstream signaling events. One of these inhibitors is Rottlerin (mallotoxin), which has been purified from Mallotus philippinensis and has been shown to differentiate between protein kinase C (PKC) isoenzymes (Gschwendt et al, 1994). Rottlerin was shown to be a powerful inhibitor of the calcium-unresponsive PKC- $\delta$ with an $\mathrm{IC}_{50}$ of $6 \mu \mathrm{M}$ for the recombinant enzyme (Gschwendt et al, 1994). Interestingly, phorbol esterinduced mouse ear edema was completely suppressed by topical application of $50 \mu \mathrm{g}$ of Rottlerin (Gschwendt et al, 1984). Rottlerin also abolished opioid-induced cardioprotection to the ischemic myocardium (Fryer et al, 2001) and blocked hyperosmotic sodium chloride-induced signaling pathways (Zhuang et al, 2000), suggesting a role for PKC- $\delta$ within these scenarios. Furthermore, based on the use of Rottlerin, PKC- $\delta$ has been implicated in the prolactin-induced relaxin $\mathrm{mRNA}$ expression in luteinized granulosa cells (Peters et al, 2000), as well as arsenite-induced signaling events (Chen et al, 2000).

However, it is difficult to assess whether one inhibitor actually is specific for only a single enzyme because it is not possible to check the in vitro as well as the in vivo specificity of a single kinase inhibitor against all the kinases available in a single cell. The widely used gene knock-out technique in mice, however, might allow verification of inhibitor specificity because selective effects of these small compounds should be mimicked by a deficiency of the respective protein.

In this report, we demonstrate by PV treatment of B cells and mast cells that PKC- $\delta$ as well as the src homology 2-containing inositol phosphatase (SHIP) are participants in the BCR transducer complex as well as in a related structure in high affinity $\lg E$ receptor (Fce $\mathrm{R} 1)$-signaling. The so-called $\mathrm{PKC}-\delta$-specific inhibitor Rottlerin inhibits PV-induced tyrosine phosphorylation in $\mathrm{B}$ and mast cells. Using PKC- $\delta$ $-/-$ mast cells, we show that the inhibitory effect of Rottlerin on PV-induced tyrosine phosphorylation events is not paralleled by PKC- $\delta$-deficiency. The role of PKC- $\delta$ seems to be a more attenuating one with respect to $F_{C} \in \mathrm{R} 1$ and $\mathrm{BCR}$ signaling and might be an important regulatory element for $B$ cell and mast cell development and function.

\section{Results and Discussion}

It has been shown by PV stimulation of BCR-positive and -negative J558L myeloma cells that tyrosine phosphorylation of certain proteins is dependent on the membrane expression of a functional BCR, indicating that the BCR organizes its own transducer complex (Wienands et al, 1996). These studies have led to the identification of SLP-65, the adapter protein responsible for the orchestration of BCR-initiated signals (Jumaa et al, 1999; Wienands et al, 1998; Wollscheid et al, 1999). To identify additional proteins of the BCR transducer complex, we used the system of PV stimulation of BCR-negative J558L cells and IgM-
BCR-positive J558L ( $\mu \mathrm{m} 3-11)$ cells. As shown in Figure 1A, stimulation of the two cell lines with $25 \mu \mathrm{M}$ PV for 2 minutes resulted in augmented tyrosine phosphorylation events in the BCR-positive $\mu \mathrm{m}$ 3-11 cell line with dominant unidentified proteins being pp80 and pp140. In the course of this study, pp80 was identified as the delta-isotype of PKC. As shown in Figure 1B using antiphosphotyrosine precipitation, PKC- $\delta$ is strongly tyrosine phosphorylated in the $\mu \mathrm{m}$ 3-11 cells, whereas almost no tyrosine phosphorylation of PKC- $\delta$ can be monitored in the parental cell line. Direct tyrosine phosphorylation of PKC- $\delta$ by PV was also observed by precipitating PKC- $\delta$ and analyzing it via antiphosphotyrosine Western blot (data not shown). Furthermore, we were able to identify pp140 as the SH2 domain-containing phosphatidylinositol polyphosphate 5'-phosphatase SHIP (Fig. 1C), which has previously been demonstrated to control BCR-induced calcium mobilization (Bolland et al, 1998). To ensure that comparable amounts of total cell lysates have been subjected to the immunoprecipitation reactions, equal volumes were immunoblotted against PKC- $\delta$ (Fig. 1D).

It is tempting to speculate that the presence of $\mathrm{PKC}-\delta$ in the BCR transducer complex might have some regulatory impact on this complex via serine/ threonine phosphorylation of other components. Therefore, we employed the PKC- $\delta$ inhibitor Rottlerin that is thought to be specific for this isotype of PKC (Gschwendt et al, 1994; Kontny et al, 2000). Intriguingly, even the use of as little Rottlerin as $5 \mu \mathrm{M}$ for 20 minutes resulted in complete inhibition of most of the PV-induced tyrosine phosphorylation events in $\mu \mathrm{m}$ 3-11 cells (Fig. 2A). Tyrosine phosphorylation of PKC- $\delta$ and SHIP was inhibited completely (not shown). Equal loading was ensured by immunoblotting with PKC- $\delta$-specific antibodies (Fig. 2B). These data indicate a major stimulatory role for $\mathrm{PKC}-\delta$ in the onset of tyrosine phosphorylation events within the BCR transducer complex and suggest the involvement of PKC- $\delta$ in B cell development and immunological function.

PKC- $\delta$ has been shown to be activated by crosslinking of FceR1 on mast cells (Song et al, 1998) and we sought to determine whether it might play a comparable role within a putative Fc $\epsilon \mathrm{R} 1$ transducer complex. In a first step, we verified that PV $(10,25$, and $50 \mu \mathrm{M})$ also induced tyrosine phosphorylation events in bone marrow-derived mast cells (BMMC) (Fig. 3A) and that $\mathrm{PKC}-\delta$ is one of these tyrosine-phosphorylated proteins (Fig. 3B). Interestingly, we identified one of the strongest PV-responsive proteins to be SHIP (Fig. 3C), suggesting that it might participate in an FceR1 transducer complex. Fitting into this picture, using wildtype and SHIP -/- BMMC, we previously found that SHIP is the gatekeeper of mast cell degranulation via the FceR1 (Huber et al, 1998), in which respect the presence of SHIP in close proximity to the receptor, even in the absence of ligand, would be a great advantage for this task. Again, equal loading was verified by anti-PKC- $\delta$ immunoblotting of total cell 

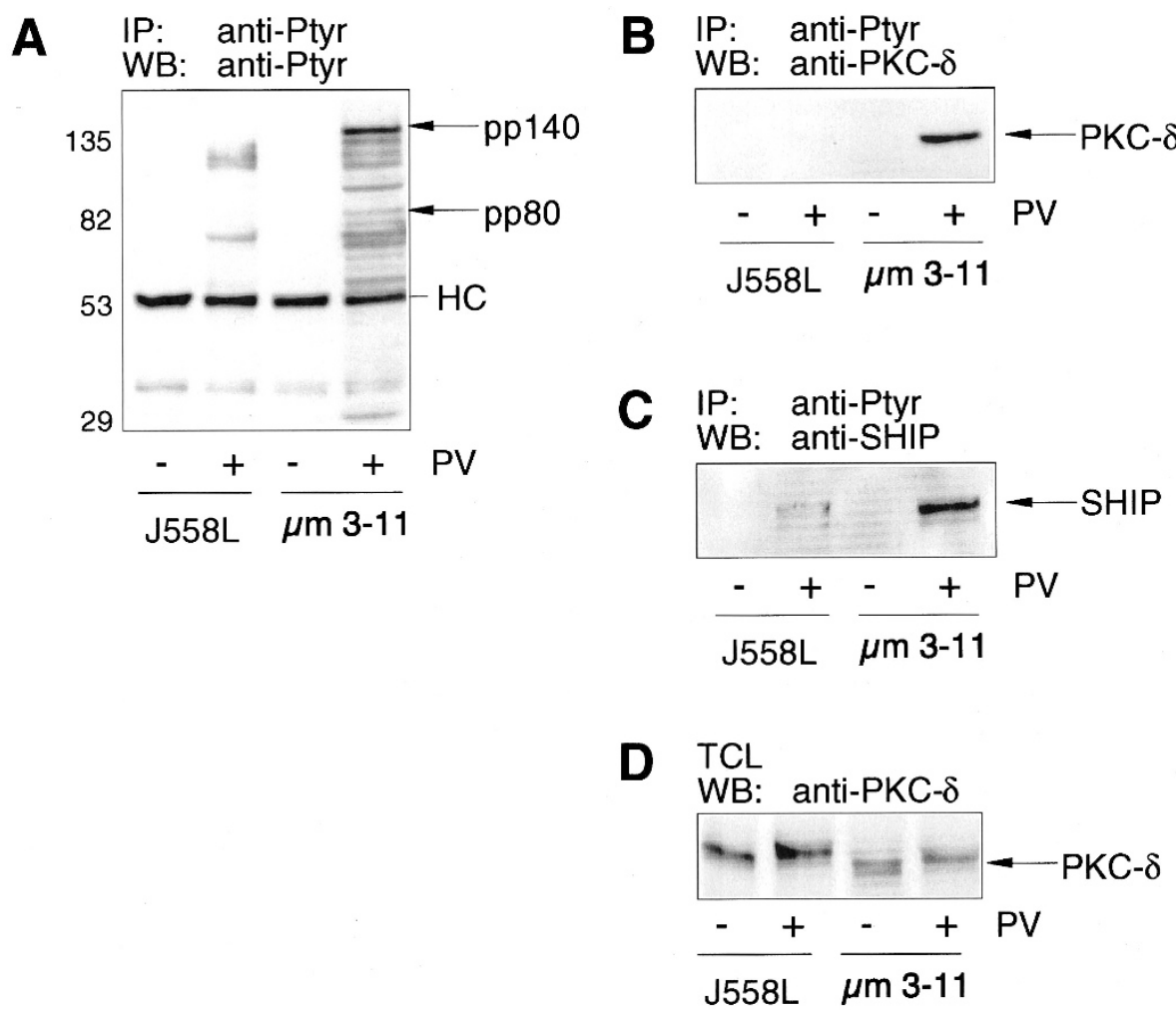

Figure 1.

Protein kinase C (PKC)- $\delta$ and src homology 2-containing inositol phosphatase (SHIP) are targets of PV stimulation in $\mu \mathrm{m}$ 3-11 B lymphocytes. A, J558L and $\mu \mathrm{m}$ 3-11 cells $\left(5 \times 10^{6}\right)$ were stimulated with $25 \mu \mathrm{M}$ PV for 2 minutes at $37^{\circ} \mathrm{C}$. The postnuclear supernatants were subjected to antiphosphotyrosine immunoprecipitation followed by antiphosphotyrosine Western blotting. Tyrosine-phosphorylated proteins pp80 and pp140 are marked with arrows, the molecular weight marker $\left(\times 10^{3}\right)$ is indicated on the left (HC, heavy chain). B, The membrane shown in Panel A was stripped and reprobed with PKC- $\delta$-specific antibodies. C, The membrane shown in Panel A was subjected to Western blotting by SHIP-specific antibodies. D, Before immunoprecipitation, total cell lysates (TCL) were analyzed by anti-PKC- $\delta$ immunoblotting to ensure equal loading. PKC- $\delta$ and SHIP are indicated with arrows.

lysates before the immunoprecipitation reactions (not shown).

Having established that PKC- $\delta$ is one of the proteins being heavily tyrosine-phosphorylated in PV-treated $B M M C$, the effect of Rottlerin was studied in this cellular system. As shown in Figure 4A, comparable to 3 to $11 \mu \mathrm{m} B$ lymphocytes, preincubation of BMMC with 5, 10, or $20 \mu \mathrm{m}$ Rottlerin for 20 minutes resulted in an almost complete inhibition of PV-induced tyrosine phosphorylation events. Tyrosine phosphorylation of PKC- $\delta$ and SHIP was completely abrogated (not shown). Equal loading was controlled by anti-PKC- $\delta$ immunoblotting of cell lysates before immunoprecipitation (Fig. 4B).

To challenge the putative central role of $\mathrm{PKC}-\delta$ within the initial transducer complex-guided tyrosine phosphorylation events in FceR1 as well as BCR signal transduction, we grew $\mathrm{PKC}-\delta-/-\mathrm{BMMC}$ via in vitro differentiation of bone marrow from PKC- $\delta-/-$ mice, the generation of which will be described elsewhere. Because we assumed that the Fc $\epsilon \mathrm{R} 1$ contributes most to the PV-induced tyrosine phosphorylation events in BMMC, using fluorescein isothiocyanate (FITC)labeled $\operatorname{lgE}$, we ensured that both $\mathrm{PKC}-\delta+/+$ and $-/-$ BMMC expressed a comparable number of Fc $\epsilon$ R1 molecules on their surfaces. The comparable FACScan profiles are shown in Figure $5 \mathrm{~A}$. PKC- $\delta$ deficiency of the PKC- $\delta-/-$ BMMC was verified by Western blotting of total cell lysates from PKC- $\delta+/+$ and $-/-$ BMMC (Fig. 5B, upper panel), and equal loading was verified by anti-Fc $\epsilon$ R1- $\beta$-chain immunoblotting (Fig. 5B, lower panel). Next, both cell types were stimulated with $25 \mu \mathrm{M}$ PV for 2 minutes and examined for tyrosine-phosphorylated proteins. Based on our Rottlerin data, it was suspected that PKC- $\delta-/-$ BMMC would show a significant reduction. As shown in Figure $6 \mathrm{~A}$, the absence of PKC- $\delta$, however, did not lead to the inhibition of PV-induced tyrosine phosphorylation events in BMMC, but surprisingly resulted in a significant increase in the extent of tyrosine phosphorylation after PV stimulation. The tyrosine phosphorylation of PKC- $\delta$ itself was, as expected, lost in the PKC- $\delta-/-$ BMMC (Fig. 6B). In this respect, Song et al (1998) reported that overexpression of $\mathrm{PKC}-\delta$ in RBL-2H3 cells resulted in the dramatic inhibition of Src activity and a weaker inhibition of Lyn activity. Moreover, PKC- $\delta$ has been shown to be activated by $\mathrm{H}_{2} \mathrm{O}_{2}$ treatment of COS-7 cells, a treatment comparable to PV (Konishi et al, 1997). PKC- $\delta$ deficiency might therefore lead to a looser control of Src family members within the transducer complex, resulting in stronger tyrosine phosphorylation of relevant substrates after PV stimulation. Because the discrepancy between the results shown in 


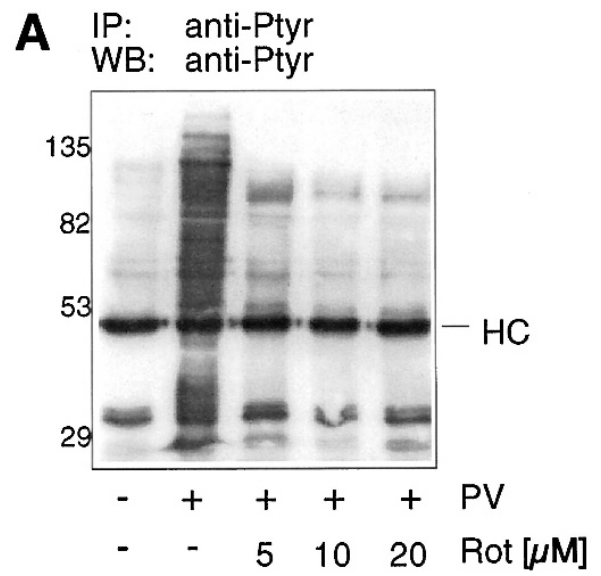

B TCL

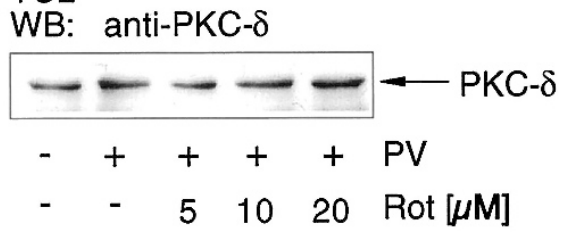

Figure 2.

Rottlerin inhibits PV-induced tyrosine phosphorylation events in $\mu \mathrm{m} 3-11$ cells. A, $\mu \mathrm{m} 3-11$ cells $\left(5 \times 10^{6}\right)$ were stimulated with $25 \mu \mathrm{m}$ PV for 2 minutes after a 20-minute incubation with vehicle (dimethyl sulfoxide [DMSO], -) or with 5,10 , or $20 \mu \mathrm{m}$ Rottlerin. Postnuclear supernatants were subjected to antiphosphotyrosine precipitation with subsequent Western analysis by antiphosphotyrosine antibodies. The molecular weight marker $\left(\times 10^{3}\right)$ is indicated on the left $(H C)$. B, Before immunoprecipitation, TCL were analyzed by anti-PKC- $\delta$ immunoblotting to ensure equal loading. PKC- $\delta$ is indicated with an arrow. $\mathrm{HC}$, heavy chain.

Figures $2 \mathrm{~A}$ and $4 \mathrm{~A}$ on one hand and Figure $6 \mathrm{~A}$ on the other hand raised certain questions about the specificity of the so-called PKC- $\delta$-specific inhibitor Rottlerin (which is used by many researchers to verify PKC- $\delta$ isotype-specific effects), we investigated PVinduced tyrosine phosphorylation events in PKC- $\delta$ $+/+$ and $-/-$ BMMC with or without preincubation with different concentrations of Rottlerin $(5,10$, and 20 $\mu \mathrm{M})$. Fitting with the above, the PV-induced tyrosine phosphorylation events in PKC- $\delta-/-$ BMMC were also strongly reduced by Rottlerin-albeit with a slightly different dose-response curve consistent with the stronger activation of tyrosine phosphorylation events-to levels comparable with those seen in wildtype BMMC (Fig. 6C). This result clearly shows that the effect of Rottlerin on PV-induced tyrosine phosphorylation events is not due to PKC- $\delta$ inhibition. Furthermore, the broad inhibitory effect on PVinduced phosphorylation events observed in this study suggests that Rottlerin is probably inhibiting more than one additional kinase and might be considered as a broad-range kinase inhibitor not suitable for the verification of PKC- $\delta$-mediated effects in cellular signaling and pathophysiological processes.

Because it was apparent that Rottlerin was not specific for the delta-isotype of PKC, we next addressed the question of whether Rottlerin is inhibiting kinases of the PKC family in general or kinases beyond

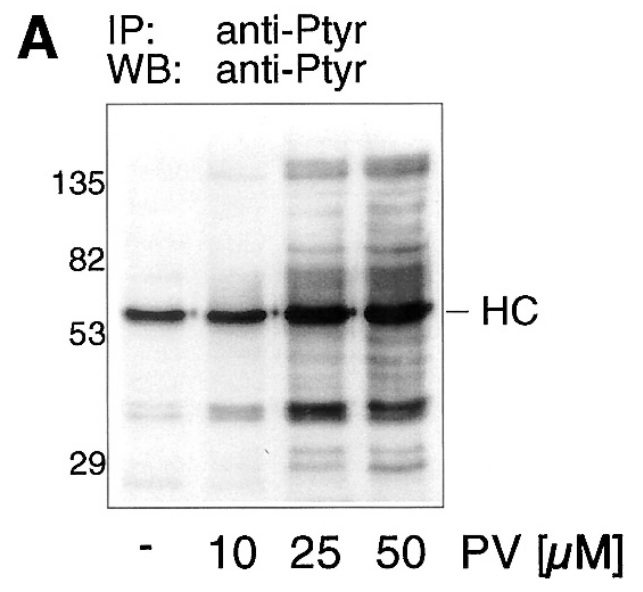

B IP: $\quad$ anti-Ptyr
WB: anti-PKC- $\delta$
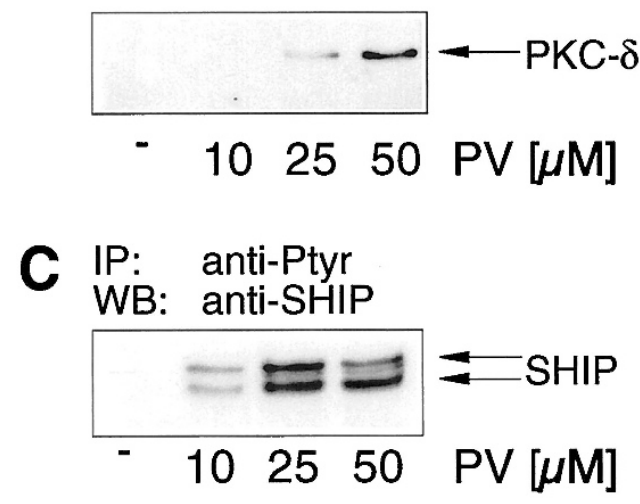

Figure 3.

Tyrosine phosphorylation of PKC- $\delta$ and SHIP in bone marrow-derived mast cells (BMMC). A, BMMC $\left(5 \times 10^{6}\right)$ were stimulated with 10,25 , or $50 \mu \mathrm{m}$ pervanadate (PV) for 2 minutes at $37^{\circ} \mathrm{C}$. Postnuclear supernatants were subjected to antiphosphotyrosine immunoprecipitation followed by antiphosphotyrosine Western blotting. Molecular weight markers $\left(\times 10^{3}\right)$ are indicated on the left $(H C)$. The membrane shown in Panel A was reprobed with PKC- $\delta$-specific antibodies (B) as well as SHIP-specific antibodies (C). PKC- $\delta$ and SHIP are indicated with arrows.

this protein family. We therefore compared Rottlerin and the panspecific PKC inhibitor bisindolylmaleimide with respect to their effects on $\mathrm{PV}$-induced tyrosine

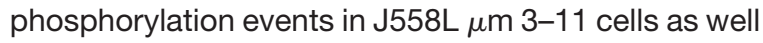
as in BMMC. The PI3K inhibitor LY294002 was used as a control. Whereas Rottlerin $(5 \mu \mathrm{M})$ completely inhibited PV-induced tyrosine phosphorylation events, bisindolylmaleimide at a concentration $(25 \mu \mathrm{M})$ sufficient to abolish BMMC degranulation (Huber et al, 2000) did not result in a significant change in the pattern of tyrosine-phosphorylated proteins (Fig. 7A). LY294002 treatment was comparable to treatment with bisindolylmaleimide (Fig. 7A). Equal loading was verified by anti-PKC- $\delta$ immunoblotting of the lysates before antiphosphotyrosine immunoprecipitation (not shown). This result clearly suggests that Rottlerin is capable of inhibiting kinases, which are not members of the PKC family. Whether Rottlerin is, in vivo, specifically inhibiting PKC family members at all cannot be answered at this stage of the project. We further 
A IP: anti-Ptyr

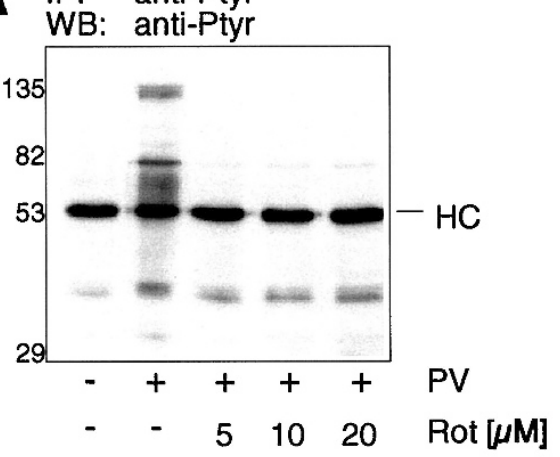

B TCL

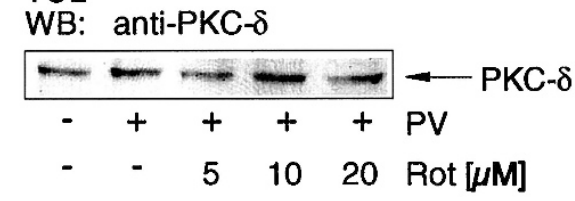

Figure 4.

Inhibition of tyrosine phosphorylation events in BMMC by Rottlerin. A, BMMC $\left(5 \times 10^{6}\right)$ were stimulated with $25 \mu \mathrm{M}$ PV for 2 minutes after a 20-minute incubation with vehicle (DMSO, -) or 5, 10, or $20 \mu \mathrm{M}$ PKC- $\delta$ inhibitor Rottlerin. Postnuclear supernatants were subjected to antiphosphotyrosine precipitation with subsequent antiphosphotyrosine Western analysis. The molecular weight marker $\left(\times 10^{3}\right)$ is indicated on the left $(H C)$. B. Before immunoprecipitation, TCL were analyzed by anti-PKC- $\delta$ immunoblotting to ensure equal loading. PKC- $\delta$ is marked with an arrow.

analyzed phosphorylation of protein kinase $B(P K B)$ at serine 473 in BMMC in response to $P V$ in the absence and presence of the three different inhibitors. As shown in Figure 7B, $5 \mu \mathrm{m}$ Rottlerin was capable of inhibiting PKB phosphorylation equally well as $100 \mu \mathrm{M}$ of the PI3K inhibitor LY294002. The panspecific PKC inhibitor did not inhibit PKB Ser473 phosphorylation (Fig. 7B), again suggesting a PKC-unrelated effect of Rottlerin. Equal loading was verified by anti-PKC- $\delta$ Western blotting (Fig. 7C). The same pattern of inhibition on PKB Ser473 phosphorylation was obtained in PV-stimulated $\mu \mathrm{m}$ 3-11 B cells (not shown). The possibility that Rottlerin directly inhibits PKB cannot be excluded.
In the paper introducing Rottlerin as a PKC- $\delta$ selective inhibitor, Gschwendt et al (1994) stated that the tyrosine kinase activity of Src could not be suppressed by Rottlerin at concentrations up to $100 \mu \mathrm{M}$. Because tyrosine kinases of the Src family, especially Lyn, are thought to be the first kinases activated after BCR (Reth and Wienands, 1997) and Fc $\epsilon$ R1 engagement (Daeron, 1997), the question arises whether inhibition of serine/threonine kinases by Rottlerin might be capable of causing the dramatic effects on tyrosine phosphorylation events shown in this paper (Figs. 2, 4, 6, and 7). In this respect, Müller et al reported that serine/threonine kinases can negatively regulate tyrosine-based signal transduction of the $\mathrm{BCR}$, and in light of our data, this might suggest a role for PKC- $\delta$. It has also been shown that for Fc $\epsilon$ R1, nontyrosine phosphorylation of the receptor can have an important impact on receptor-induced tyrosine phosphorylation events. Swann et al (1999) have reported that threonine 60 of the FceR1 $\gamma$-chain is phosphorylated on receptor engagement. Mutation of threonine 60 to alanine resulted in inhibition of FceR1induced TNF- $\alpha$ mRNA production, as well as inhibition of degranulation (Swann et al, 1999). However, because the kinase phosphorylating threonine 60 of the $\gamma$-chain has an augmenting role for FceR1-triggered tyrosine phosphorylation events, there might be no involvement of PKC- $\delta$ in this scenario.

Lu et al (1997) showed that depleting rat fibroblasts that overexpressed the c-Src proto-oncogene of PKC- $\delta$ by long-term phorbol ester treatment resulted in the induction of transformation-related phenotypes, suggesting a role for $\mathrm{PKC}-\delta$ in attenuating tumor promotion and indicating functional interaction between c-Src and PKC- $\delta$ (Lu et al, 1997). This interesting study made use of a well-established dominant negative form of PKC- $\delta$ (K376A) (Hirai et al, 1994; Li et al, 1995), the overexpression of which paralleled the tumor-promoting effect of the phorbolester (Lu et al, 1997). In a further step, by using the so-called PKC$\delta$-specific inhibitor Rottlerin, it was shown that Rottlerin treatment (30 $\mu \mathrm{M}, 24$ hours) resulted in a comparable tumor promotion (Lu et al, 1997). In light of our data, it seems likely that the observed tumor-
A

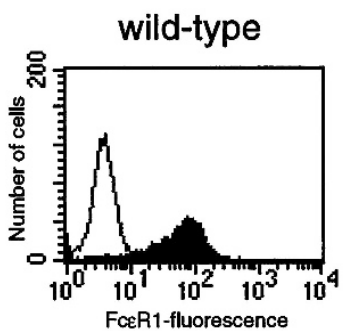

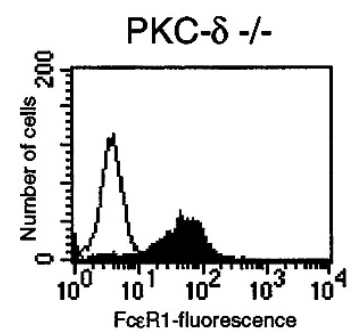

B

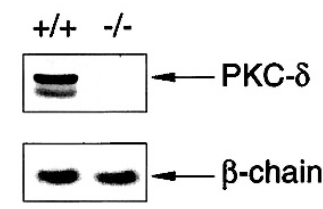

Figure 5.

PKC- $\delta+/+$ and $-/-$ BMMC express comparable amounts of surface high affinity IgE receptor (Fc $\epsilon$ R1). A, Cell surface expression of Fc $\epsilon$ R1 in BMMC from PKC- $\delta$ $+/+$ and $-/-$ mice was assessed by a FACScan with fluorescein isothiocyanate (FITC)-labeled IgE (anti-Erythropoietin 26) (gray line). No FITC-labeled IgE staining was observed with Fc $\epsilon$ R1-negative J558L cells that served as the background control (black line). B, PKC- $\delta+/+$ and $-/-$ BMMC were lysed and analyzed by anti-PKC- $\delta$ (upper panel) and by anti-Fc $\epsilon$ R1- $\beta$-chain (lower panel) Western blotting. 
promoting effect of Rottlerin in rat fibroblasts is not due to Rottlerin inhibiting PKC- $\delta$, but might be due to the inhibition of an inhibitory-acting kinase. In fact, stimulating Rottlerin-treated mast cells with PV results in the appearance of a slow-migrating form of the FceR1- $\beta$-chain in SDS-polyacrylamide gels, which is not apparent after PV treatment alone, and in addition can be detected in wild-type as well as PKC- $\delta-/-$ BMMC (not shown).

It appears to be a common theme in the PKC- $\delta$ analyzing literature that PKC- $\delta$-specific effects are determined by means of expressing dominantnegative mutants (Braiman et al, 1999; Chen et al, 1999; Efimova and Eckert, 2000; Hornia et al, 1999; Lu et al, 1997; Majumder et al, 2000; Vuong et al, 2000) or the regulatory domain (Sun et al, 2000) of PKC- $\delta$, as well as antisense mRNA strategies (Corbit et al, 2000; Liedtke and Cole, 1997). To verify the data generated with these valid tools, Rottlerin is generally used to independently prove the PKC- $\delta$ specificity of the measured effect. According to our data, Rottlerin is not a valid tool for verifying PKC- $\delta$-specific effects in cellular signal transduction. This does not cast doubt on the findings from the dominant-negative or antisense approaches; however, data with respect to the PKC- $\delta$ specificity of a certain effect based only on the use of Rottlerin should be viewed with caution because they might be erroneous (Chen et al, 2000; Frasch et al, 2000; Fryer et al, 2001; Peters et al, 2000; Reyland et al, 1999; Zheng et al, 2000; Zhuang et al, 2000). Rottlerin has been shown in various publications to inhibit apoptosis triggered by proapoptotic factors, such as etoposide and ultraviolet B-light (Chen et al, 1999; Reyland et al, 1999). This effect of Rottlerin is also probably not due to its inhibiting PKC- $\delta$, but to inhibition of another not-yet characterized enzyme or pathway.

In conclusion, our data show that PKC- $\delta$ is a likely component of the BCR transducer complex, as well as of a related structure of the Fc $\in \mathrm{R} 1$ on mast cells. Using PKC- $\delta-/-$ BMMC, we show that PV-induced tyrosine phosphorylation events are augmented, suggesting an attenuating role of PKC- $\delta$ in FceR1 and BCR signaling; additional projects are underway to strengthen this concept. One might speculate that PKC- $\delta$ is a critical signaling element setting the threshold for mast cell activation (eg, degranulation and cytokine expression), thereby being important for the control and development of allergic diseases. In contrast, we found the so-called PKC- $\delta$-selective kinase inhibitor Rottlerin to inhibit PVinduced tyrosine phosphorylation events in $\mathrm{B}$ and mast cells. Moreover, Rottlerin inhibited tyrosine phosphorylation events in PKC- $\delta$-deficient BMMC, proving that this inhibitor is unspecific and not suitable for distinguishing between PKC- $\delta$-dependent and -independent signaling events.

\section{Materials and Methods}

\section{Cell Culture}

The J558L myeloma cells and the IgM-BCR expressing J558L cell line $\mu \mathrm{m} 3-11$ were maintained $\left(37^{\circ} \mathrm{C}\right.$,
$5 \% \mathrm{CO}_{2}$ ) in RPMI 1640 medium supplemented with $10 \%$ fetal calf serum (FCS), $2 \mathrm{~mm}$ L-glutamine, 50 units $/ \mathrm{mL}$ penicillin, $50 \mathrm{mg} / \mathrm{mL}$ streptomycin, and 200 $\mathrm{mm}$ 2-mercaptoethanol. Surface IgM expression was proved by staining the cells with FITC-labeled goatantimouse IgM antibody (Southern Biotechnology/ Biozol, Eching, Germany) and analyzing the cells with a FACScan (Becton Dickinson, Franklin Lakes, New Jersey). Bone marrow cells $\left(1 \times 10^{6} / \mathrm{mL}\right)$ from 4 - to 8-week-old wild-type and PKC- $\delta-/$ - mouse littermates (129/Sv x C57BL/6) were cultured $\left(37^{\circ} \mathrm{C}, 5 \%\right.$ $\mathrm{CO}_{2}$ ) in a single cell suspension in Iscove's modified Dulbecco's medium containing 20\% FCS, $1 \%$ X63Ag8-653-conditioned medium as a source of IL-3 (Karasuyama and Melchers, 1988), 2 mm L-glutamine,
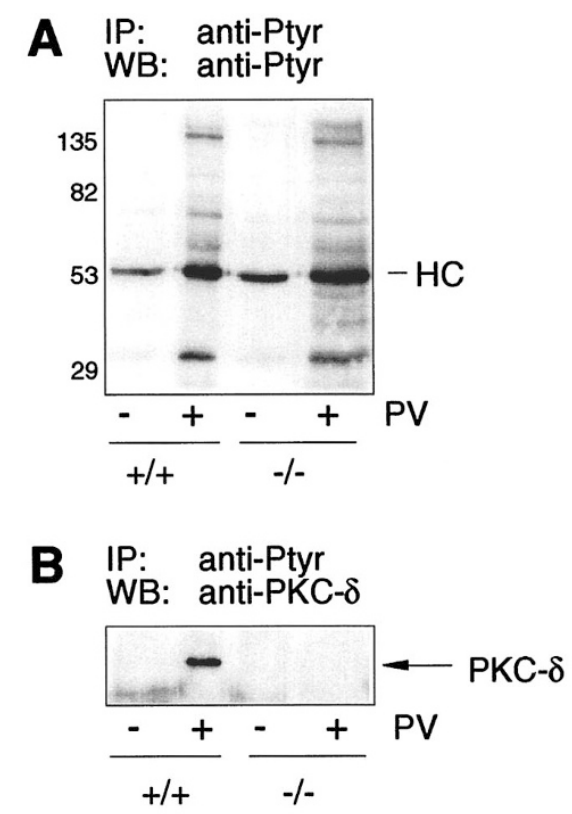

\section{IP: anti-Ptyr \\ WB: anti-Ptyr}

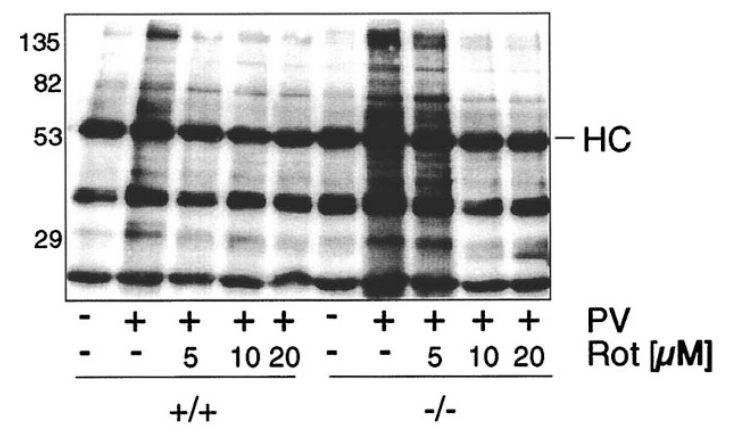

Figure 6.

PKC- $\delta$-independent effect of Rottlerin. A, PKC- $\delta+/+$ and $-/-$ BMMC $(5 \times$ $10^{6}$ ) were stimulated with $25 \mu \mathrm{M}$ PV for 2 minutes. Postnuclear supernatants were subjected to antiphosphotyrosine immunoprecipitation followed by antiphosphotyrosine Western blotting. Molecular weight markers $\left(\times 10^{3}\right)$ are indicated on the left $(H C)$. B, The membrane shown in Panel A was stripped and reprobed with PKC- $\delta$-specific antibodies. PKC- $\delta$ is indicated with an arrow. C, PKC- $\delta+/+$ and $-/-$ BMMC $\left(5 \times 10^{6}\right)$ were stimulated with $25 \mu \mathrm{M}$ PV for 2 minutes after a 20-minute incubation with vehicle (DMSO, -) or 5 , 10 , or $20 \mu \mathrm{m}$ Rottlerin. Lysates were subjected to antiphosphotyrosine precipitation with subsequent antiphosphotyrosine Western blot analysis. 
A IP: anti-Ptyr

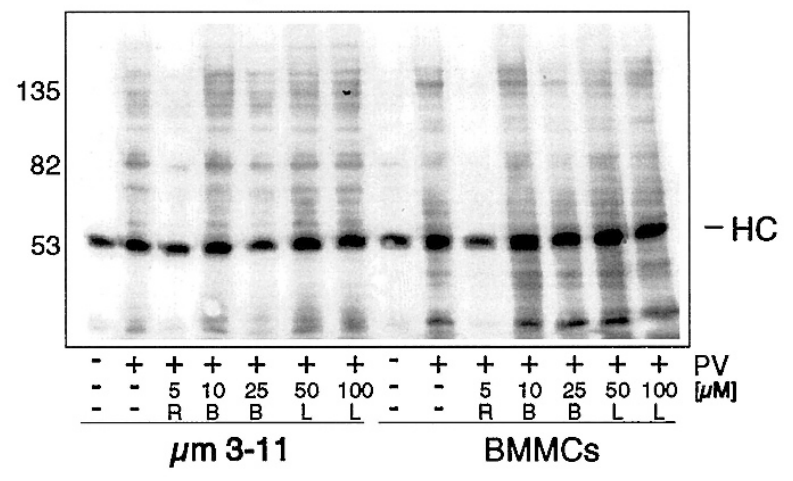

B TCL

WB: anti-pPKB

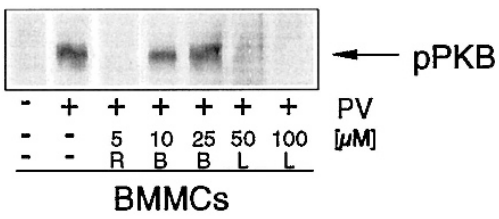

C TCL

WB: anti-PKC- $\delta$

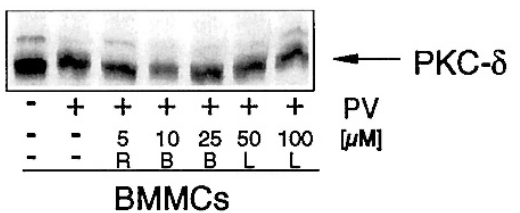

Figure 7.

PKC-independent effect of Rottlerin. A, $\mu \mathrm{m} 3-11$ cells and wild-type BMMC $\left(5 \times 10^{6}\right)$ were stimulated with $25 \mu \mathrm{M}$ PV for 2 minutes after a 20 -minute incubation with vehicle (DMSO, -), $5 \mu \mathrm{m}$ Rottlerin $(R), 10$ or $25 \mu \mathrm{m}$ bisindolylmaleimide $(B)$, or 50 or $100 \mu \mathrm{m}$ LY294002 (L). Postnuclear supernatants were subjected to antiphosphotyrosine precipitation followed by Western analysis with antiphosphotyrosine antibodies. The molecular weight marker $\left(\times 10^{3}\right)$ is indicated on the left $(H C)$. B, BMMC were treated as described under Panel A, and TCL were analyzed by antiphosphorylated protein kinase B (PKB) (B) and anti-PKC- $\delta$ immunoblotting (C). Phosphorylated PKB $(p P K B)$ and PKC- $\delta$ are indicated with arrows.

$1 \times 10^{-5} \mathrm{~m} 2$-mercaptoethanol, 50 units/mL penicillin, and $50 \mathrm{mg} / \mathrm{mL}$ streptomycin. At weekly intervals, the nonadherent cells were reseeded at $1 \times 10^{6}$ cells $/ \mathrm{mL}$ in fresh medium. By 5 to 8 weeks of culture, more than 99\% of the cells were c-kit and FceR1 positive as assessed by phycoerythrin-labeled anti-c-kit antibodies (Pharmingen, Mississauga, Ontario, Canada) and FITC-labeled lgE (anti-erythropoietin 26), respectively.

\section{Chemicals and Antibodies}

Rottlerin, bisindolylmaleimide I, and LY294002 were purchased from Calbiochem (Schwalbach, Germany). Polyclonal antibodies against Ser473 phosphorylated PKB were obtained from New England Biolabs (Mississauga, Ontario, Canada). Polyclonal anti-SHIP antibodies (anti-N and anti-M; Damen et al, 1998) and FITC-labeled IgE (antierythropoietin 26) were a gift from Dr. G. Krystal. The monoclonal anti-FceR1- $\beta$-chain antibody was generously provided by Dr. R. Siraganian. The monoclonal antiphosphotyrosine antibody coupled to agarose (PT66) used for immunoprecipitations was purchased from Sigma (Taufkirchen, Germany) and the monoclonal antiphosphotyrosine antibody 4G10 used for Western blotting was purchased from Biozol (Eching, Germany). Polyclonal anti-PKC- $\delta$ antibody $(C-17)$ was obtained from Santa Cruz (Heidelberg, Germany).

\section{PV Stimulation, Immunoprecipitation, and Western Blotting}

The PV solution was prepared according to Baumann et al (1994). Cells were washed in PBS and resuspended $\left(5 \times 10^{6} / \mathrm{mL}\right)$ in Tyrode's buffer $(130 \mathrm{~mm} \mathrm{NaCl}$, $5 \mathrm{~mm} \mathrm{KCl}, 1.4 \mathrm{~mm} \mathrm{CaCl}_{2}, 1 \mathrm{~mm} \mathrm{MgCl}_{2}$, $5.6 \mathrm{~mm}$ glucose, and $0.1 \%$ bovine serum albumin (BSA) in $10 \mathrm{~mm}$ Hepes, $\mathrm{pH}$ 7.4). Cells were adapted to $37^{\circ} \mathrm{C}$ for 30 minutes and stimulated with the indicated concentra- tions of PV. Signal transduction inhibitors were added to the sample after the adaption phase and 20 minutes before PV addition. After stimulation, cells were pelleted and solubilized with $0.5 \% \mathrm{NP}-40$ in $4^{\circ} \mathrm{C}$ phosphorylation solubilization buffer $(500 \mu l)$ (Liu et al, 1994). Thirty microliters of the total cell lysate were directly separated by SDS-PAGE and subjected to Western blot analysis as described previously (Liu et al, 1994). The remaining lysate was subjected to immunoprecipitation with three subsequent washing steps with PSB containing $0.1 \% \mathrm{NP}-40$. The precipitate was separated by SDS-PAGE and analyzed by Western blotting. Stripping of the membranes for sequential reprobing was carried out according to Jugloff and Jongstrabilen (1997).

\section{Acknowledgements}

We thank Dr. G. Krystal for the gift of FITC-labeled anti-Epo IgE as well as anti-SHIP antibodies and Dr. R. Siraganian for the generous provision of $\beta$-chainspecific antibodies. We further thank Dr. M. Reth for his generous support and critical discussions. This work is supported by the Deutsche Forschungsgemeinschaft through grant SFB 388 and the Leibniz prize to Dr. M. Reth.

\section{References}

Baumann G, Maier D, Freuler F, Tschopp C, Baudisch K, and Wienands J (1994). In vitro characterization of major ligands for Src homology 2 domains derived from protein tyrosine kinases, from the adaptor protein SHC and from GTPaseactivating protein in Ramos B cells. Eur J Immunol 24:17991807.

Bolland S, Pearse RN, Kurosaki T, and Ravetch JV (1998). SHIP modulates immune receptor responses by regulating membrane association of Btk. Immunity 8:509-516. 
Braiman L, Alt A, Kuroki T, Ohba M, Bak A, Tennenbaum T, and Sampson SR (1999). Protein kinase $C-\delta$ mediates insulin-induced glucose transport in primary cultures of rat skeletal muscle. Mol Endocrinol 13:2002-2012.

Campbell KS, Bedzyk WD, and Cambier JC (1995). Manipulation of $\mathrm{B}$ cell antigen receptor tyrosine phosphorylation using aluminum fluoride and sodium orthovanadate. Mol Immunol 32:1283-1294.

Chen NY, Ma WY, Huang C, Ding M, and Dong Z (2000). Activation of PKC is required for arsenite-induced signal transduction. J Environ Pathol Toxicol Oncol 19:297-305.

Chen N, Ma W, Huang C, and Dong Z (1999). Translocation of protein kinase Cepsilon and protein kinase $\mathrm{C}-\delta$ to membrane is required for ultraviolet B-induced activation of mitogen-activated protein kinases and apoptosis. J Biol Chem 274:15389-15394.

Corbit KC, Soh JW, Yoshida K, Eves EM, Weinstein IB, and Rosner MR (2000). Different protein kinase $C$ isoforms determine growth factor specificity in neuronal cells. Mol Cell Biol 20:5392-5403.

Daeron M (1997). Fc receptor biology. Annu Rev Immunol 15:203-234.

Damen JE, Liu L, Ware MD, Ermolaeva M, Majerus PW, and Krystal G (1998). Multiple forms of the SH2-containing inositol phosphatase, SHIP, are generated by C-terminal truncation. Blood 92:1199-1205.

Efimova T and Eckert RL (2000). Regulation of human involucrin promoter activity by novel protein kinase C isoforms. J Biol Chem 275:1601-1607.

Frasch SC, Henson PM, Kailey JM, Richter DA, Janes MS, Fadok VA, and Bratton DL (2000). Regulation of phospholipid scramblase activity during apoptosis and cell activation by protein kinase Cdelta. J Biol Chem 275:23065-23073.

Fryer RM, Wang YG, Hsu AK, and Gross GJ (2001). Essential activation of PKC- $\delta$ in opioid-initiated cardioprotection. Am J Physiol Heart Circ Physiol 280:H1346-H1353.

Gschwendt M, Kittstein W, Furstenberger G, and Marks F (1984). The mouse ear edema: A quantitatively evaluable assay for tumor promoting compounds and for inhibitors of tumor promotion. Cancer Lett 25:177-185.

Gschwendt M, Muller HJ, Kielbassa K, Zang R, Kittstein W, Rincke G, and Marks F (1994). Rottlerin, a novel protein kinase inhibitor. Biochem Biophys Res Commun 199:93-98.

Hecht D and Zick $Y$ (1992). Selective inhibition of protein tyrosine phosphatase activities by $\mathrm{H}_{2} \mathrm{O}_{2}$ and vanadate in vitro. Biochem Biophys Res Commun 188:773-779.

Hirai S, Izumi Y, Higa K, Kaibuchi K, Mizuno K, Osada S, Suzuki K, and Ohno S (1994). Ras-dependent signal transduction is indispensable but not sufficient for the activation of AP1/Jun by PKC $\delta$. EMBO J 13:2331-2340.

Hornia A, Lu Z, Sukezane T, Zhong M, Joseph T, Frankel P, and Foster DA (1999). Antagonistic effects of protein kinase $\mathrm{C} \alpha$ and $\delta$ on both transformation and phospholipase D activity mediated by the epidermal growth factor receptor. Mol Cell Biol 19:7672-7680.

Huber M, Helgason CD, Damen JE, Liu L, Humphries RK, and Krystal G (1998). The src homology 2-containing inositol phosphatase (SHIP) is the gatekeeper of mast cell degranulation. Proc Nat Acad Sci USA 95:11330-11335.
Huber M, Hughes MR, and Krystal G (2000). Thapsigargininduced degranulation of mast cells is dependent on transient activation of phosphatidylinositol-3 kinase. J Immunol 165:124-133.

Imbert V, Peyron JF, Farahi Far D, Mari B, Auberger P, and Ross B (1994). Induction of tyrosine phosphorylation and T-cell activation by vanadate peroxide, an inhibitor of protein tyrosine phosphatases. Biochem J 297:163-173.

Jugloff LS and Jongstrabilen J (1997). Cross-linking of the IgM receptor induces rapid translocation of IgM-associated $\lg \alpha$, Lyn, and Syk tyrosine kinases to the membrane skeleton. J Immunol 159:1096-1106.

Jumaa $\mathrm{H}$, Wollscheid B, Mitterer $\mathrm{M}$, Wienands J, Reth $\mathrm{M}$, and Nielsen PJ (1999). Abnormal development and function of B lymphocytes in mice deficient for the signaling adaptor protein SLP-65. Immunity 11:547-554.

Karasuyama $\mathrm{H}$ and Melchers $\mathrm{F}$ (1988). Establishment of mouse cell lines which constitutively secrete large quantities of interleukin 2, 3, 4 or 5, using modified cDNA expression vectors. Eur J Immunol 18:97-104.

Konishi H, Tanaka M, Takemura $\mathrm{Y}$, Matsuzaki $\mathrm{H}$, Ono $\mathrm{Y}$, Kikkawa $U$, and Nishizuka $Y$ (1997). Activation of protein kinase $\mathrm{C}$ by tyrosine phosphorylation in response to $\mathrm{H}_{2} \mathrm{O}_{2}$. Proc Nat Acad Sci USA 94:11233-11237.

Kontny E, Kurowska M, Szczepanska K, and Maslinski W (2000). Rottlerin, a PKC isozyme-selective inhibitor, affects signaling events and cytokine production in human monocytes. J Leukoc Biol 67:249-258.

Li W, Yu JC, Shin DY, and Pierce JH (1995). Characterization of a protein kinase $\mathrm{C}-\delta$ (PKC- $\delta$ ) ATP binding mutant: An inactive enzyme that competitively inhibits wild type PKC- $\delta$ enzymatic activity. J Biol Chem 270:8311-8318.

Liedtke CM and Cole T (1997). Antisense oligodeoxynucleotide to PKC-delta blocks alpha 1-adrenergic activation of Na-K-2Cl cotransport. Am J Physiol 273:C1632-C1640.

Liu L, Damen JE, Cutler RL, and Krystal G (1994). Multiple cytokines stimulate the binding of a common 145-kilodalton protein to Shc at the Grb2 recognition site of Shc. Mol Cell Biol 14:6926-6935.

Lu Z, Hornia A, Jiang YW, Zang Q, Ohno S, and Foster DA (1997). Tumor promotion by depleting cells of protein kinase C $\delta$. Mol Cell Biol 17:3418-3428.

Majumder PK, Pandey P, Sun XG, Cheng KD, Datta R, Saxena S, Kharbanda S, and Kufe D (2000). Mitochondrial translocation of protein kinase $\mathrm{C} \delta$ in phorbol ester-induced cytochrome C release and apoptosis. J Biol Chem 275: 21793-21796.

Minegishi Y, Rohrer J, Coustan-Smith E, Lederman HM, Pappu R, Campana D, Chan AC, and Conley ME (1999). An essential role for BLNK in human B cell development. Science 286:1954-1957.

Müller R, Wienands J, and Reth M (2000). The serine and threonine residues in the Ig-alpha cytoplasmic tail negatively regulate immunoreceptor tyrosine-based activation motifmediated signal transduction. Proc Natl Acad Sci USA 97: 8451-8454.

O'Shea JJ, McVicar DW, Bailey TL, Burns C, and Smyth MJ (1992). Activation of human peripheral blood T lymphocytes by pharmacological induction of protein-tyrosine phosphorylation. Proc Nat Acad Sci USA 89:10306-10310. 
Peters CA, Maizels ET, Robertson MC, Shiu RP, Soloff MS, and Hunzicker-Dunn M (2000). Induction of relaxin messenger RNA expression in response to prolactin receptor activation requires protein kinase $\mathrm{C} \delta$ signaling. Mol Endocrinol 14:576-590.

Reth M and Wienands J (1997). Initiation and processing of signals from the B cell antigen receptor. Annu Rev Immunol 15:453-479.

Reyland ME, Anderson SM, Matassa AA, Barzen KA, and Quissell DO (1999). Protein kinase $C \delta$ is essential for etoposide-induced apoptosis in salivary gland acinar cells. J Biol Chem 274:19115-19123.

Secrist JP, Burns LA, Karnitz L, Koretzky GA, and Abraham RT (1993). Stimulatory effects of the protein tyrosine phosphatase inhibitor, pervanadate, on T-cell activation events. J Biol Chem 268:5886-5893.

Song JS, Swann PG, Szallasi Z, Blank U, Blumberg PM, and Rivera J (1998). Tyrosine phosphorylation-dependent and -independent associations of protein kinase C-delta with Src family kinases in the RBL-2H3 mast cell line: Regulation of Src family kinase activity by protein kinase $\mathrm{C}-\delta$. Oncogene 16:3357-3368

Sun X, Wu F, Datta R, Kharbanda S, and Kufe D (2000). Interaction between protein kinase $\mathrm{C}$ delta and the $\mathrm{C}-\mathrm{Abl}$ tyrosine kinase in the cellular response to oxidative stress. J Biol Chem 275:7470-7473.

Swann PG, Odom S, Zhou YJ, Szallasi Z, Blumberg PM, Draber $P$, and Rivera J (1999). Requirement for a negative charge at threonine 60 of the FcRgamma for complete activation of Syk. J Biol Chem 274:23068-23077.
Vuong $\mathrm{H}$, Patterson T, Shapiro P, Kalvakolanu DV, Wu R, Ma WY, Dong ZG, Kleeberger SR, and Reddy SPM (2000). Phorbol ester-induced expression of airway squamous cell differentiation marker, SPRR1B, is regulated by protein kinase C $8 /$ Ras/MEKK1/MKK1-dependent/AP-1 signal transduction pathway. J Biol Chem 275:32250-32259.

Wienands J, Larbolette O, and Reth M (1996). Evidence for a preformed transducer complex organized by the $\mathrm{B}$ cell antigen receptor. Proc Nat Acad Sci USA 93:7865-7870.

Wienands J, Schweikert J, Wollscheid B, Jumaa H, Nielsen PJ, and Reth M (1998). SLP-65: A new signaling component in $B$ lymphocytes which requires expression of the antigen receptor for phosphorylation. J Exp Med 188:791-795.

Wollscheid B, Wienands J, and Reth M (1999). The adaptor protein SLP-65/BLNK controls the calcium response in activated B cells. Curr Top Microbiol Immunol 246:283-289.

Zheng WH, Kar S, and Quirion R (2000). Stimulation of protein kinase $\mathrm{C}$ modulates insulin-like growth factor-1induced akt activation in PC12 cells. J Biol Chem 275:1337713385.

Zhuang S, Hirai SI, and Ohno S (2000). Hyperosmolality induces activation of $\mathrm{CPKC}$ and $\mathrm{nPKC}$, a requirement for ERK1/2 activation in NIH/3T3 cells. Am J Physiol 278:C102C109. 